\title{
DOPPLER ULTRASONOGRAPHY WAVEFORMS CHANGES IN IUGR AND THEIR VALUES IN THE RELEVANT MANAGEMENT OF PREGNANCY
}

\author{
Arian Kashami ${ }^{1}$, Amela Troshani ${ }^{2}$, Zamira Shabani $^{3}$ \\ ${ }^{1,2}$ University Hospital of Obstetrics and Gynecology "Koço Gliozheni”, Tirana, Albania; \\ ${ }^{3}$ Faculty of Natural Science, University of Shkodra, Albania; \\ E-mail: ${ }^{1}$ ariankashami@gmail.com; ${ }^{2}$ troshaniamela@gmail.com; ${ }^{3}$ shabanizamira@yahoo.com
}

Received February, 2018; Accepted March, 2018; Published April, 2018;

doi: https://doi.org/10.31407/ijees833

UOI license: http://u-o-i.org/1.01/ijees/57264641

\begin{abstract}
Intrauterine Growth Restriction (IUGR) means the ultrasonography recording by estimated foetal weight (EFW) below than $10^{\text {th }}$ percentile for its gestational age. This group includes foetuses that do not reach their genetic potential for intrauterine growth and indicates a small foetus that is deprived compared to the previous ultrasonography assessment (usually for a placental reason). This retrospective study includes unique complicated pregnancies with IUGR, between 26-37 weeks GA, in the years 2014-2017 and is performed in University Hospital of Obstetrics and Gynecology "Koço Gliozheni", in Tirana, Albania. The inclusion criteria in this study were: the exact age of pregnancy (LMGA or from the ultrasound before 20 weeks); EFW in ultrasound < p.10th; the early beginning of placental insufficiency is when PI > p.95th for GA and CPR $<1.04$; all of the pregnant women included in this study had more than three Doppler ultrasonography examinations before delivery, where Doppler parameters of $\mathrm{AU}$ were obtained: presence of diastole, absence or reverse flow. Patients with chromosomal anomalies have been excluded from the study. The monitoring intervals and the moment of birth were done by the doctors who followed the pregnancy. Neonatal features, birth details, indications and birth delivery, age of pregnancy, birth weight, Apgar, are recorded for each patient. In the baby's birth day were recorded all the changes in the Doppler and the progression of Doppler abnormalities from one examination to the other. Although is calculated the time from the occurrence of abnormal Doppler until the baby was born.
\end{abstract}

Key words: age, artery, growth, gestational, intrauterine, restriction, umbilical. 